\title{
Circuito da violência no sistema socioeducativo: do mito à falácia da socioeducação
}

\author{
The cycle of violence in the socio-educational system: from the myth to the fallacy of
} socio-education

Bruna Carolina BONALUME*

https://orcid.org/oooo-0002-4109-5435

Adriana Giaqueto JACINTO**

https://orcid.org/oooo-0003-0181-2839

Resumo: O artigo tem como objetivo desenvolver uma análise crítico-reflexiva sobre as tensões e contradições que atravessam a socioeducação no tempo presente. Para isso aborda as manifestações da violência perpetuada pelos dispositivos do Estado, que controlam o percurso punitivo dirigido a adolescentes e jovens que cometem atos infracionais, entre esses, o próprio Sistema Socioeducativo. Resulta de uma pesquisa social qualitativa, fundamentada no materialismo histórico dialético e que adotou a entrevista em profundidade como estratégia metodológica para recolha dos dados com oito jovens que cumpriam a medida socioeducativa em meio aberto. A partir desse percurso, concluímos que a violência institucional se revela como uma das formas bárbaras que permeiam o sistema socioeducativo brasileiro e favorece a sua incorporação mais a um sistema penal do que ao sistema de garantia de direitos.

Palavras-chave: Socioeducação. Estado. Controle Sociopenal. Violência.

Abstract: This article develops a critical reflexive analysis of the tensions and contradictions that currently crisscross socio-education. It addresses the manifestations of violence perpetuated by the State bodies that control the punitive pathway directed at adolescents and young people who commit infractions, including the Socio-Educational system. It results from qualitative social research, based on historical dialectical materialism, and adopts, as a methodological strategy for data collection, in-depth interviews with eight young people who were exposed to socio-educational measures in an open environment. We conclude that institutional violence is one of the barbaric forms that permeate the Brazilian socio-educational system and lends itself more to being incorporated into a penal system than a system that guarantees rights.

Keywords: Socio-education. State. Socio-penal Control. Violence.

Submetido em: 26/6/2020. Revisado em: 30/9/2020. Aceito em: 13/10/2020.

\begin{abstract}
*Assistente Social. Doutora em Serviço Social. Docente da graduação em Serviço Social da UNIFAC. (Associação de Ensino de Botucatu). Endereço institucional: Avenida Leonardo Villas Boas, 351 Botucatu/SP. Assistente Social do Tribunal de Justiça do Estado de São Paulo. (TJSP, São Paulo, Brasil). Rua Etore Targa, s/nº, São Manuel (SP), CEP: 18650-0oo. E-mailbruna.bonalume@hotmail.com.

${ }^{* *}$ Assistente Social. Pós Doutora em Serviço Social. Docente da graduação e pós graduação em Serviço Social na Universidade Estadual Paulista (UNESP)- Faculdade de Ciências Humanas e Sociais, campus de Franca. (UNESP, Franca, Brasil). Avenida Eufrásia Monteiro Petráglia, 90o, Jardim Dr. Antonio Petráglia, Franca (SP), CEP.: 14409-160. E-mail: drigiaqueto@gmail.com.
\end{abstract} copiar e redistribuir o material em qualquer suporte ou formato, bem como adaptar, transformar e criar a partir deste material para qualquer fim, mesmo que comercial. O licenciante não pode revogar estes direitos desde que você respeite os termos da licença. 


\section{Introdução}

$\mathrm{V}$

ivemos em uma sociedade que instrumentaliza a violência, a punição e o controle social da pobreza e sua reprodução social, o que, evidentemente, impacta a condição de vida de adolescentes e jovens, sobretudo quando a esses é atribuída a prática de ato infracional. Para além das aparências, a violência se constitui como um fenômeno plural, multifacetado que ganha pulso com o modo de produção capitalista em um Brasil atravessado por contradições, orientações ideológicas e políticas que se constroem no solo histórico e fértil de uma sociedade desigual. Sociedade esta regida pelo capital, cujas raízes estruturais estão fincadas nos escombros do colonialismo, na barbárie da escravidão, no poder da oligarquia e no capitalismo tardio e periférico.

Nessa direção, cabe destacar que o capitalismo em toda sua lógica de expansão sempre se apresentou como um sistema desigual, alicerçado na exploração de uma classe sobre a outra. Podemos assim afirmar que as desigualdades sociais, consolidadas nesse modelo vigente de sociedade, são resultado da riqueza socialmente produzida e acessada por poucos. A pobreza alastra-se e aumenta a distância entre ricos e pobres no Brasil, o que denuncia uma realidade na qual a ampliação das riquezas contrasta fortemente com o aprofundamento da miséria e, com isso, o crescente processo de pauperização, insegurança, violência, precarização e exploração do trabalho vão se tornando traços permanentes e integrantes dessa sociedade dividida em classes.

Nesse contexto, tem-se um Estado que não se intimida em reprimir a gigantesca massa de miseráveis engendrada pela reestruturação contemporânea do capital. Ao contrário disso, sua intervenção se pauta no fortalecimento da coerção, o que evidencia a audaciosa manutenção da ordem estabelecida, dos distintos lugares a serem ocupados nessa divisão de classes socialmente estabelecida, que desenha a relação entre o aparato estatal coercitivo e pobreza sob a vigência neoliberal. Todas estas questões têm como pano de fundo assegurar a falácia de que a expansão desse Estado é um complemento indispensável para assegurar a regulação do mercado de trabalho e seu domínio.

É por essa via que chegamos ao cenário atual, no qual o neoliberalismo se alastra em tamanha velocidade que nem mesmo o tempo consegue lhe impor barreiras e, estando em plena capacidade de expansão, propaga projetos societários que nada condizem com os interesses da classe trabalhadora e da massa empobrecida que a compõe. Ao contrário disso, adota um alinhamento político cada vez mais radical a favor de uma minoria burguesa e impõe condições severas que retroalimentam as desigualdades sociais e intensificam as expressões da questão social.

Temos, desta forma, um contexto marcado pelo (des) financiamento das políticas sociais, a mercantilização em seu estágio universal, o culto ao individualismo e a banalização da violência a partir de discursos de ódio que se propagam, sobretudo em direção às adolescências e juventudes pobres, negras e periféricas. A esse contexto soma-se, ainda, um ultraconservadorismo que se reedita e se fortalece na cena contemporânea. 
Essa conjuntura nos permite afirmar, ainda, que mesmo com toda a trajetória histórica de luta, resistência e intensa mobilização social que resultou na promulgação do Estatuto da Criança e do Adolescente (ECA), principal marco normativo de promoção e defesa dos direitos de crianças e adolescentes, e posteriormente na Lei do SINASE ${ }^{1}$ (BRASIL, 2012), ainda não é possível afirmarmos que a lógica de proteção integral e efetivação de direitos dos adolescentes e jovens esteja consolidada. O que temos é uma linha tênue entre o discurso da proteção e da punição, que se manifesta nas contradições de um arcabouço normativo consolidado no bojo de uma sociedade de classes, portanto, essa proteção se traveste de coerção e integra a formulação de um projeto societário destinado a determinados grupos sociais.

Portanto, se revisitarmos a trajetória sócio-histórica da justiça juvenil brasileira, estaremos diante de duas faces de uma mesma moeda. De um lado os inegáveis avanços do ECA, que orienta a justiça brasileira, no que se refere ao reconhecimento de crianças e adolescentes como sujeitos de direitos e sua inserção no circuito dos direitos humanos. Do outro, porém, não podemos adotar a postura ingênua de ignorar que essa luta está inscrita numa dinâmica neoliberal, permeada por uma ideologia dominante. Desta forma, mesmo tendo decorrido 30 anos da promulgação do ECA e 7 anos da Lei do SINASE, ainda permanecemos atônitos diante da velha questão que coloca o adolescente e o jovem brasileiro entre a escassa proteção e o devasso controle repressivo.

A partir dessas considerações, objetiva-se no presente artigo desenvolver uma análise crítica e reflexiva sobre as tensões e contradições que atravessam a socioeducação no tempo presente. Adentrar nesse cenário árido exigiu das autoras a escolha de um arcabouço teórico-metodológico crítico e alinhado a uma rigorosa análise para que a construção do conhecimento ultrapassasse as fronteiras da superficialidade e da fragmentação, e, por essa razão, o estudo pautou-se no materialismo histórico dialético. Sua produção resulta de uma pesquisa social realizada no processo de doutoramento, a qual adotou a abordagem qualitativa e utilizou como estratégia metodológica para a recolha de dados a entrevista em profundidade com oito jovens que cumpriam medida socioeducativa em meio aberto e já haviam vivenciado a experiência da privação da liberdade, em um município do interior paulista, no período de janeiro a março de 2019.

A recolha de dados ocorreu no espaço no Centro de Referência Especializado de Assistência Social (CREAS) ${ }^{2}$. As entrevistas, por serem em profundidade, não tiveram

\footnotetext{
${ }^{1}$ O SINASE- Sistema Nacional de Atendimento Socioeducativo é um instrumento composto por um "[...] conjunto ordenado de princípios, regras e critérios, de caráter jurídico, político, pedagógico, financeiro e administrativo, que envolve desde o processo de apuração de ato infracional até a execução de medida socioeducativa" (BRASIL, 2006, p. 22). Trata-se, portanto, de uma política pública intersetorial voltada à garantia de direitos de adolescentes que venham a cometer atos infracionais. (BRASIL, 2006)

2 O CREAS é uma unidade pública da política de Assistência Social onde são atendidas famílias e pessoas que estão em situação de risco social ou tiveram seus direitos violados. Dentre os serviços ofertados está o das Medidas Socioeducativas em Meio Aberto, ou seja, de liberdade assistida e prestação de serviço à comunidade que tem por finalidade prover atenção socioassistencial e o acompanhamento considerando a responsabilização dos adolescentes. Este acompanhamento deve ter
} 
um roteiro estruturado, porém foi elaborado um instrumento para orientação das pesquisadoras. Sua aplicação durou em média 70 minutos e foram transcritas na íntegra e apresentadas aos entrevistados para se manifestarem em torno da narrativa. Esse momento foi deixado livre para que pudessem suprimir falas, acrescentar outras, modificar ou corrigir, bem como para que pudessem manifestar a sua concordância.

A pesquisa foi submetida ao Comitê de Ética e procurou seguir no decorrer do processo todos os preceitos éticos. O tratamento analítico dos dados se deu com base no próprio método do materialismo histórico dialético, considerando as categorias epistemológicas inerentes ao mesmo, quais sejam: totalidade, contradição, mediação e historicidade, juntamente com as categorias violência, controle sociopenal e violação de direitos.

\title{
I Violência: uma expressão do controle sociopenal?
}

\author{
"Do rio que tudo arrasta se diz que é violento. Mas \\ ninguém diz violentas as margens que o comprimem”
}

(Bertolt Brecht)

A violência apresenta-se como uma categoria ampla, heterogênea, multifacetada, inscrita no complexo circuito das determinações sócio-históricas da humanidade, que vai se reconfigurando e se reeditando no cerne da sociedade capitalista. Para Ianni (2002), a violência não cabe em um conceito, uma ideia ou interpretação, dada a sua complexidade e suas múltiplas manifestações "[...] coletivas e individuais, históricas e psicológicas, objetivas e subjetivas [...]” (IANNI, 2002, p. 8) e, por essa razão, destaca o autor que a violência possui uma excepcionalidade que "[...] transborda das várias ciências sociais; revela dimensões insuspeitadas da realidade social, ou da história, em suas implicações político-econômicas, socioculturais, objetivas e subjetivas" (IANNI, 2002, p. 8).

Em termos conceituais, Engels (2017) faz uma relação entre violência e desenvolvimento econômico. O autor defende que a violência acelera o processo econômico e, portanto, constitui-se em um instrumento para legitimação, expansão e domínio do capital:

[...] a violência não é um mero ato de vontade, pressupondo, pelo contrário, condições prévias bastante reais para o seu exercício, a saber: instrumentos, entre os quais, o mais perfeito esmaga o mais imperfeito. Estes instrumentos, que não brotam do solo por si sós, tiveram de ser produzidos, o que equivale a dizer que o produtor dos mais perfeitos instrumentos de violência, que são as armas, triunfa sobre o produtor dos mais imperfeitos. Daí, temos de reconhecer, em resumo, que a vitória da violência se reduz à produção de armas e que esta, por sua vez, se reduz à produção em geral, e, portanto, ao 'poderio econômico', à 'situação econômica', aos meios materiais colocados à disposição da vontade de violência (ENGELS, 2017, p. 145).

frequência mínima semanal visando, desta forma, a garantir ação continuada por meio de acompanhamento sistemático (BRASIL, 2009). 
No Brasil, segundo Chauí (2000), há o poderoso mito "[...] da não violência brasileira [...]" (CHAUÎ, 200o, p. 36), quando na verdade, para a autora, se nos reportarmos para o processo de formação sócio-histórico da nossa sociedade veremos que a violência tem acompanhado essa formação desde sua gênese.

A imagem do mito fundador, segundo Chauí (2000), idealiza circunstâncias e status que encobrem e naturalizam a violência, a desigualdade e a cultura de subserviência. Para a autora, essa ideia de que em nossas terras convivem harmonicamente diferentes raças, etnias, credos e culturas, desempenhou um papel ideológico fundamental para mascarar as tensões de uma sociabilidade profundamente marcada em suas origens por estruturas desiguais, de concentração de renda e de autoritarismo. Por essa razão, conclui que "[...] a violência é o ar que respiramos, as ações que praticamos, interiorizada e realizada nas relações pessoais, sociais, econômicas e políticas" (CHAUÍ, 2013, p. 242).

Nessa mesma direção, para Minayo (2006) essa violência, tal como se expressa hoje, possui cunho coletivo e tem como base interesses econômicos, pois se constitui, primordialmente, como condição de manutenção de negócios ilegais, de cunho globalizado e que se beneficiam das facilidades geradas pelas transformações nos modos de produção de riqueza e dos aparatos técnico-informacionais e comunicacionais. Conclui a autora que a violência gera lucros e cita como exemplo a expansão legalizada do comércio de armas e, por essa razão, afirma que em qualquer projeto ou proposta de superação e $\backslash$ ou enfrentamento da violência, é importante que a sociedade se pergunte: quem lucra com ela? E se ela gera lucro, a quem interessa criar um projeto societário pautado em uma sociabilidade não violenta?

Nesse sentido, pensar em violência significa pensar em estruturas de dominação, cujo fundamento se encontra na apartação dos trabalhadores dos meios necessários à produção das riquezas socialmente produzidas. Significa colocar em conflito o capital como um sistema em cujo processo o valor significa uma "[...] relação social [...]" (HARVEY, 2013, p. 41), um meio de produção e de obtenção de mais-valia que gera estruturas desiguais, alienantes.

Por essa razão, para Ianni (2002), a trama de relações e o jogo de forças que emanam da sociedade contemporânea capitalista se constituem também como uma "[...] fábrica de violência [...]" (IANNI, 2002, p. 7), que carrega consigo formas, técnicas e práticas cada vez mais brutais, "[...] desde as mais prosaicas às mais sofisticadas [...]" (IANNI, 2002, p. 7) e se reproduz pelos mais diversos estratos sociais, mas é junto à população de pobres e miseráveis, as então classes perigosas, que ela ganha notoriedade e tom de alarde e clamor social.

E aqui adentramos no campo de contradições: as situações de violência e de violação de direitos que atravessam a vida de adolescentes e jovens, principalmente se a eles já foi atribuída a prática de um ato infracional, em geral não mobilizam na sociedade qualquer incômodo, ou indignação; é o que Sales (2007) chamou de "[...] invisibilidade perversa [...]" (SALES, 2007, p. 25). Quando esses mesmos meninos e meninas protagonizam qualquer ato de violência, seja esse considerado grave ou não, ganham 
ampla visibilidade e tornam-se alvo predileto da grande mídia e dos discursos para o endurecimento da punição a eles destinada, em relação a isso novamente destacamos o projeto em curso para a redução da maioridade penal. Trata-se, portanto, "[...] de uma condição de visibilidade perversa, seletiva e reprodutora de discriminações históricas contra os setores mais pauperizados e insubmissos das classes trabalhadoras" (SALES, 2007, p. 27).

Nesse contexto, é válido destacar que a socioeducação insere-se no processo de acumulação capitalista, no conjunto de ações estratégicas do Estado, que legitima seu compromisso com a manutenção da ordem e controle social, mesmo que para isso se torne necessário apoiar-se em projetos societários que nada condizem com as ações socioeducativas de cunho crítico e emancipatório. Por essa razão, consideramos que a violência no contexto da socioeducação, além de se constituir como uma expressão da questão social que emerge do solo árido desse capitalismo selvagem e impiedoso, é também uma categoria que emana das relações postas pelo controle sociopenal direcionado às adolescências e juventudes.

Assim, consideramos falacioso o discurso que atribui ao Sistema Socioeducativo a ideia de proteção integral dos adolescentes e jovens que cometem atos infracionais, pois estamos diante de um sistema cuja violência estrutural está enraizada e alinhada às instituições que historicamente foram responsáveis por gerenciar esse circuito de violações, a exemplo disso, a antiga Fundação Estadual para o Bem-Estar do Menor (FEBEM), e no tempo presente são reeditadas outras formas de menorismo.

Nesse sentido, com base na análise de Baratta (1993), podemos considerar que esse discurso protetivo da medida socioeducativa nada mais é do que um mecanismo ideológico apto a justificar, legitimar e naturalizar a violência perpetuada contra as adolescências e juventudes e que implica, como apontou o autor, na repressão de necessidades reais e, portanto, violação ou suspensão de direitos humanos. É no bojo desse debate que podemos afirmar que as manifestações da violência no sistema socioeducativo travestem-se de aspectos econômicos, políticos, sociais, culturais, etnicorraciais, tendo como pano de fundo os antagonismos de um país cujas desigualdades sociais tão profundas são parte de uma herança desastrosa de seu próprio processo sócio-histórico.

\section{A violência no contexto da socioeducação na voz dos jovens}

As discussões e análises postas nessa seção passam a ser, agora, a trajetória de vida daqueles que protagonizaram a nossa pesquisa, sendo, portanto, o lugar de fala de oito meninos entrevistados entre janeiro de março de 2019 no interior do estado de São Paulo. A direção ideopolítica que conduz nossas análises é exatamente a voz silenciada desses sujeitos, a qual nos permitiu conhecer vidas, não de 'menores infratores', mas de jovens. Torna-se importante destacar aqui que, como forma de preservar a identidade desses sujeitos, os nomes foram alterados e escolhidos pelos próprios jovens.

Considerando o limite da proposta do presente artigo, iremos nos debruçar sobre os dados que retratam a experiência vivida por esses meninos no momento em que 
cumpriam a medida socioeducativa de internação. E sobre isso a primeira questão que nos inquieta é a seletividade do sistema socioeducativo, alvo do controle sociopenal, pois não nos parece coincidência que os protagonistas desse estudo, embora com as devidas peculiaridades e singularidades, carreguem tantas semelhanças entre si ou na mesma direção de pesquisas institucionais que se propõem a estudar a socioeducação.

Estamos diante de sujeitos do sexo masculino. Dos oito participantes, quatro se declaram negros, três se declaram pardos e apenas um se declara branco. Somente um jovem não reside nas áreas consideradas periféricas do município. Quanto à faixa etária, Gustavo está com 19 anos, Maganha, Tom e Independente estão com 18 anos, Leo, Mágico e Marquinhos, 17 anos e Lucas 16 anos.

Quanto à tipificação do ato infracional, no momento da pesquisa seis meninos cumpriam a medida socioeducativa por terem cometido ato infracional análogo ao tráfico de drogas e os outros dois garotos, análogos ao furto, sendo que todos os jovens estavam inseridos na medida de LA como progressão da internação que estavam cumprindo anteriormente. Tom cumpriu a primeira internação quando tinha apenas 13 anos, Lucas 14 anos, Leo, Marquinhos, Mágico e Independente aos 15 anos. Maganha e Gustavo foram os únicos que cumpriram primeiro a medida socioeducativa em meio aberto, porém, quando ambos estavam com 16 anos também viveram a experiência da privação da liberdade e aqui emana outra inquietação: a via de ingresso no sistema socioeducativo desses sujeitos, visto que essa se deu de forma bastante precoce e, sobretudo, pela via da internação, embora nenhum dos meninos tenha cometido atos infracionais mediante ações violentas, com posse de armas, ou mesmo homicídios. Todavia, contraditoriamente, foram alvos de ações violentas praticadas pelas instâncias de controle sociopenal como discutiremos na sequência.

As experiências dos jovens no sistema socioeducativo foram relembradas pelos meninos e narradas com muita riqueza de detalhes, e muito embora esses contribuam de forma significativa com a pesquisa, contraditoriamente também nos revelam uma face cruel que demarca a falácia da socioeducação no cenário brasileiro.

Tomamos como ponto de partida para compreender a dinâmica violenta que atravessa o Sistema Socioeducativo a própria rotina institucional - marcada pelo rígido controle constante das atividades -, a autonomia reduzida, a tensão da convivência cotidiana entre os meninos, os medos, inseguranças e muita solidão:

Eu tava com 13 anos quando fui a primeira vez pra FEBEM, eu peguei internação direto. Fiquei lá um ano e seis meses. [...] Foi ruim pra caralho ficar lá viu, não tinha nada de bom lá. Tinha que acordar cedo, estudar, fazer curso que eu não queria [...] Os funcionários eles eram tipo folgadão queria vim bater nos outros, acha que você tá preso lá, então não pode conversar com ninguém, você tem que ficar no seu canto, eu falava pra eles - não sou cego, não sou surdo e não sou mudo. Mas aí eles levavam você pro cantinho lá e dava umas porradas e fazia você ficar quieto ainda. (TOM)

A convivência ali é foda, pessoas diferentes, pessoas de todo tipo, horários pra tudo, críticas, julgamentos, é indecisões é uma coisa muito pesada, abalava a gente. Todo dia igual, deixa você nervoso, tem dias que você não dormia [...] É uma rotina muito tensa ali, você fica louco, perde a cabeça se não tiver foco.[...] Na Fundação é assim né, sentado entre quatro paredes, então eu ia lá sentava 
assim e ficava sozinho analisando tudo né. Ficar privado da liberdade é muito difícil. Porque é bem regrado né, tem hora pra tudo assim, até no momento livre tem regra, na hora que a gente ia pra quadra, jogar bola. Eu não desejo isso pra ninguém. (INDEPENDENTE)

Ah mas lá é foda é muita pressão [...] Todo dia tinha que acordar de manhã, seis horas da manhã, pega uma lixa, pega uma ducha, depois era café, ficava assistindo até a hora do almoço ou ia pra escola que tinha lá. Daí ia pro almoço, a tarde era escola de novo, daí tinha distração depois da escola, tinha futebol, tênis de mesa, depois ia pro descanso de novo, tomar uma ducha, jantava às vezes, pegava uma tela, daí a gente ia dormir. Mas tem dia que você não consegue dormir, um monte de coisa passa na sua cabeça, você ali sozinho, longe da sua família, é muito foda. (MAGANHA)

Chama a atenção nas narrativas dos meninos o quanto as relações reproduzidas nesses espaços é um reflexo daquelas já vividas na própria sociedade, ou seja, a lógica do disciplinamento, a violência, o controle, a vigilância, aspectos esses que não condizem com uma proposta que, a princípio, deveria ter um cunho socioeducativo. Esse espaço normalizador da ordem, mesmo com as devidas particularidades, indica uma dinâmica semelhante ao cárcere, ao privilegiar, por exemplo, a disciplina e o rígido controle de horários, atividades, comportamentos, além de estabelecer um padrão homogeneizado com vestimentas obrigatórias, corte de cabelo (raspados) e até mesmo a forma de comunicação dos garotos, haja vista o popular 'senhora e senhor' predominantes na linguagem dos egressos da Fundação CASA.

Podemos citar, como parte desse poder de disciplinamento, outros mecanismos comuns no cotidiano da Fundação CASA: o enfileiramento, o controle excessivo do tempo a partir de horários rígidos para o estabelecimento das atividades e a perda de seus pertences pessoais e da própria identidade que passa a ser agora homogeneizada no conjunto geral da Instituição. Para Foucault (2014), isso representa uma forma de investimento político no corpo por relações de poder e de dominação, tendo em vista que o corpo, na perspectiva do autor, só se torna útil se ao mesmo tempo for produtivo e submisso. Além disso, o corpo sendo utilizado como estratégia de controle, por uma lógica e ordem de produção que requer uma padronização sobre esses meninos, tem como foco a ação disciplinadora na manutenção e garantia da ordem na operacionalização das ações cotidianas. Portanto, quando nos propomos a analisar as narrativas dos meninos para além das aparências, o que vemos são mecanismos disciplinadores em essência, que deixam clara a função das instituições que compõem o Sistema Socioeducativo, ou seja, punir para disciplinar e tornar esses garotos dóceis e produtivos ao mundo do trabalho capitalista.

Nesse sentido, consideramos parte integrante da falácia do sistema socioeducativo a prevalência de discursos que emanam tanto dos operadores sociojurídicos, como também da mídia e das instâncias de controle do Estado, cuja centralidade da medida de internação aplica-se em defesa do próprio adolescente e do jovem como forma de protegê-lo do 'colosso do crime'. Importa destacar que a defesa da privação da liberdade em prol de assegurar tanto a proteção como os direitos desses sujeitos mostra-se tão frágil como o próprio Sistema Socioeducativo, pois, como destaca Uriarte (2006), a privação da liberdade não se configura como um fator de redução da 
vulnerabilidade, ao contrário disso, ela a reproduz ao passo que amplia a exposição dos sujeitos sociais ao sistema penal.

Nessa direção, os jovens aqui entrevistados de forma majoritária relatam situações de violência severa sofrida pelos agentes socioeducativos, punições, humilhações e sofrimento, inclusive com aplicação de castigos, que incluem o isolamento naquilo que eles chamaram de 'tranca'. As narrativas indicaram, ainda, relações violentas entre os adolescentes e jovens, como forma de disputar espaço, status, entre outros:

Tem, tem muita agressão, eu mesmo apanhei, eu apanhei lá dentro, fui parar no hospital, que eu fiquei com problema no intestino até hoje. Apanhei de um funcionário, eu nunca sofri agressão igual a essa na minha vida, eles me agrediram, peguei fui pro pronto socorro, desmaiei né, aí eu caíi da maca, eu acordei com ele me ajudando me levantar. Quando eu voltei para a Fundação, os caras ficaram me olhando, tipo de um jeito pra que eu não falasse nada pra diretora que eles tinham me batido. Um deles chegou e me falou que se eu abrisse a boca, eu ia passar o resto do meu tempo lá apanhando. (GUSTAVO)

Tinha muita violência lá vixe, muita, muita. Da primeira vez o lugar onde eu fiquei era tranquilo com os funcionários, a violência era mais entre os adolescentes, os moleques apanhavam batido, apanhavam dos outros moleques, era uma cena que vou falar pra você, foda viu. [...] Na segunda vez eu vi muita coisa, de chegar e a pessoa está tendo até convulsão de tanto ser agredida, a convulsão mesmo, uma atrás do outra, de funcionário trancar toda a cela, pra ninguém ver aquilo. (INDEPENDENTE)

[...] Lá dentro não tem moleque santo, tem moleque que dá trabalho, difícil lidar, mas acho que bater não devia ser uma opção. (MÂGICO)

[...] teve um funcionário, nossa eu passei mal na mão dele, ele nunca colocou a mão em mim, mas ele me impediu de ter saidinha, eu tive a saidinha externa de campo, a saidinha que eu mais queria, ele foi lá e falou que eu estava mandando na cadeia inteira, nunca mandei [...] não é porque eu tô conversando que eu mando na cadeia. Eu sei o que ele faz, ele sabe o que eu faço, então cada um responde pelos seus atos, eu podia estar com papo cabeça lá, por que tem que ser do crime? Não é por que eu estou sentado aqui com você, que eu estou conversando sobre o crime, ou outra coisa, posso estar conversando sobre a vida, os caras não, acabou, tá bolinho já vamos mandar trancar no quarto e deixava trancado, porque ele era o coordenador, aí quando tava pra ir embora, ele me chamou assim, ele falou assim, eu lembro até hoje, ele falou assim: você vai morrer na mão dos polícia [...] E eu fui guardando, ele foi a única pessoa da minha vida que até hoje eu tive ódio foi ele. (TOM)

Tinha umas punição lá também. Tinha lá a tranca, vamos supor, agressão fisica, é uma coisa que se relar vai pra tranca uns meses e tem outras punições que você fica sem ir em áreas externas, que você fica trancado, só não tira visitas de família, essas coisas, dos seus benefícios que você tem lá dentro, que você já tem ou que não tem, que você tem que aproveitar, muitas pessoas acabam não aproveitando, porque acabam se envolvendo, brigando, então você não caminha muito lá dentro. (INDEPENDENTE)

A violência institucionalizada é traduzida pelas narrativas dos jovens como parte intrínseca do Sistema Socioeducativo, o que nos revela uma grave expressão da violação dos direitos desses meninos, além de nos remeter à forma histórica de como a 
política de atenção a esses sujeitos se estrutura no Brasil, ou seja, é alinhada a uma perspectiva punitiva, repressora e de controle sociopenal.

Nessa lógica, podemos afirmar que a medida socioeducativa da internação se constitui como uma estratégia punitiva do Estado e, sendo assim, reconhecida e legitimada, comporta com naturalidade e frieza essa expressão da violência estatal, colocando 'embaixo do tapete' qualquer indício de violação de direitos humanos desses sujeitos sociais. Como se não bastasse a violência experimentada 'ao fio da navalha', esses meninos agora vivenciam nova manifestação da violência, travestida, no entanto, de socioeducação.

Temos, então, um cenário de ambiguidades que nos leva a questionamentos: - como assegurar a proteção desses meninos no Sistema Socioeducativo? Se estamos falando em proteção no próprio espaço institucional, que socioeducação é essa de fato? Como poderíamos pensar uma socioeducação emancipadora, crítica, cidadã e ética, em condições tão severas de violência?

É por essa razão que entendemos que socioeducação vai do mito à falácia. Segundo Chauí (2000) o mito possui, além de um sentido etimológico (cuja narrativa centra-se nos feitos lendários da comunidade), um sentido antropológico, o qual tem a sua narrativa pautada na "[...] solução imaginária para tensões, conflitos e contradições que não encontram caminhos para serem resolvidos no nível da realidade" (CHAUÍ, 2ooo, p. 5). Já o termo falácia vem do latim fallacia e expressa algo enganoso. Assim, parece haver no cerce da socioeducação um discurso que não se aproxima da realidade concreta, dos problemas concretos que atravessam, sobretudo, as instituições de medida com privação ou restrição da liberdade, sendo um discurso enganoso, o qual, quando propagado, contribui para a transformação dos adolescentes e jovens que cometem ato infracional em verdadeiros inimigos públicos, como dito por Batista (2003).

Portanto, a quem interessa saber sobre as violações vividas por esses meninos no sistema socioeducativo? A quem incomodam as notícias que circulam cotidianamente denunciando práticas violentas contra esses sujeitos sociais? Parece ser mais conveniente atribuir a violência a essas adolescências e juventudes, pois assim justificase esse silêncio proposital e populariza-se amplamente a necessidade de puni-los severamente, pelo bem comum e harmônico da sociedade. E como a sociedade é dividida em classes, uma dessas precisa ser culpada e responsabilizada pelos males que atingem a parte considerada 'ordeira', no caso, os puníveis e também matáveis são aqueles que também vivem na miserabilidade do capital.

Nessa perspectiva, intensificam-se as ações do controle sociopenal em seu caráter estruturalmente seletivo, discriminatório e estigmatizante, sendo essas propagadas por todo aparato estatal e dirigidas a esses sujeitos sociais em condições de maior vulnerabilidade social (tendo em vista a intensificação das expressões da questão social), tornando-os também alvo em potencial das medidas mais duras e discriminatórias do Estado. É assim que Baratta (2019) afirma que o controle 
sociopenal cumpre a função de reprodução e manutenção da violência estrutural, e, por conseguinte, da estratificação social (BARATTA, 2019).

É preciso, ainda, destacar a invisibilidade da denúncia e o silêncio que se perpetuam nesse espaço institucional. Os garotos, também de forma majoritária, não levaram à frente as situações de violência sofridas, apenas Gustavo destacou a sua indignação e as tentativas de ser ouvido:

Ninguém escuta a gente, os agentes mandavam lá, o diretor escuta o que eles falam, o que ele passar pro diretor, o diretor vai acatar, porque a palavra deles lá dentro é que tem mais peso que a nossa, a gente precisava até ter que fazer alguma coisa que chamasse a atenção do diretor pra entrar lá dentro e conseguir falar com ele, por que os coordenadores mentiam, não falavam a verdade.(GUSTAVO)

A narrativa de Gustavo revela que a invisibilidade desses garotos no espaço institucional acaba sendo tão significativa que, no caso do jovem, a alternativa encontrada para chamar a atenção do diretor foi praticando uma ação indisciplinar, cuja consequência também seria a punição. Mas o fato é que essa invisibilidade representa a ausência de reconhecimento dos direitos desses meninos que foram violados em um espaço cujas diretrizes e normativas primam pela proteção integral.

Nessa direção, Mendez (2017) afirma que o Sistema Socioeducativo é atravessado por uma crise, a qual "[...] se configura quando o velho não acaba de morrer e o novo não acaba de nascer [...]” (MENDEZ, 2017, p. 40), ou seja, ainda estamos impregnados da cultura menorista, tutelar, de modelos que não se esgotaram com o tempo. Para o autor, o sistema de responsabilidade juvenil não está voltado ao enfrentamento das questões que emanam da criminalidade juvenil, mas tem como foco administrar de forma transparente, democrática e racional os conflitos decorrentes do envolvimento infracional de adolescentes e jovens, o que não basta para superar a lógica de um sistema que se mantém configurado como um sistema penal.

$\mathrm{O}$ autor ainda nos provoca ao destacar que além de olharmos internamente para as medidas socioeducativas, ou seja, se de fato estão sendo garantidoras de direitos e cumprindo uma função pedagógica, educativa e formativa, deveríamos nos atentar ao que o autor chama de preocupação número zero, ou seja, embora todas as outras questões se constituam como legítimas, são preocupações de número, um, dois, três. A número zero vem antes de todas essas e reside no questionamento: - "por que esses meninos estão aqui?", pois para Mendez (2017) aqui reside uma questão central que demarca a crise do Sistema Socioeducativo brasileiro que "[...] diz respeito ao problema da banalização do uso da privação de liberdade [...]” (MENDEZ, 2017, p. 42), tendo em vista o modo exacerbado como a internação vem sendo aplicada no contexto brasileiro.

Isso posto, trazer essa discussão à tona, ao mesmo tempo que constitui um desafio, dada a sua complexidade, também representa o nosso compromisso com a luta e com a denúncia das formas bárbaras e cruéis que permeiam o Sistema Socioeducativo brasileiro e que favorecem a incorporação do SINASE muito mais ao sistema penal do que ao sistema de garantia de direitos e de um cunho realmente socioeducativo. 


\section{Conclusão}

É no solo árido das discussões aqui apresentadas que esses garotos estigmatizados e rotulados pelo circuito menorista, propagado pelo intencional e seletivo processo de criminalização, tornam-se, além de produto da sociedade capitalista, objeto das agências de segurança pública do Estado e de suas instituições de controle sociopenal. Essa condição de 'produto' rouba desses garotos a vida em sua totalidade histórica, suas possibilidades de ser, existir e viver em sociedade de forma digna e humana e define o lugar que será ocupado por eles, ou seja, o da marginalidade. Desse modo, esses garotos, agora reconhecidos unicamente como 'menores infratores', irão escrever mais uma parte violenta da sua história de vida, pelo braço forte e repressivo do Estado.

A situação torna-se ainda mais alarmante se considerarmos a predominância do uso constante da violência no cotidiano dos jovens no Sistema Socioeducativo. Segundo o ECA, crianças e adolescentes/jovens contam com proteção constitucional aos direitos à liberdade, ao respeito e à dignidade como pessoas em processo de desenvolvimento e como sujeitos de direitos civis, humanos e sociais. Especifica o artigo 17 da mesma lei que o direito ao respeito, inclui: inviolabilidade da integridade física, psíquica e moral. Esses dispositivos configuram-se como diretrizes básicas e fundamentais para assegurar a proteção integral desses meninos e meninas, logo, qualquer atuação ou abordagem que se distancie desses preceitos e garantias constitucionais, e a isso se soma o silêncio social em torno das denúncias, demarca violentamente o seu papel na esfera da violação de direitos.

Aqui cabe retomarmos o questionamento - como poderíamos pensar uma socioeducação emancipadora, crítica, cidadã e ética, em condições tão severas de violência, como nos foi narrado pelos jovens? Isso nos desvela o caráter punitivo e sociodisciplinar que permeia as medidas socioeducativas, sobretudo a de internação. Além disso, as múltiplas expressões da violência estiveram presentes na trajetória de vida dos jovens em todo seu curso, na inserção precoce no circuito punitivo do Estado e na forma como as instituições que o compõem voltam a sua ação para as práticas infracionais.

Por essa razão reafirmamos que o Sistema Socioeducativo é parte integrante do Sistema Penal e carrega consigo o fardo histórico da velha roupagem menorista, punitivista, cujo pano de fundo é o controle sociopenal dirigido a esse contingente populacional, um verdadeiro celeiro que se forma sob o pretexto de um discurso pedagógico, ressocializador e protetivo.

Nesse contexto, torna-se urgente e necessário resistirmos às propostas que traduzem o desprezo pela vida das adolescências e juventudes, o indiscriminado avanço penal sobre esses sujeitos sociais, a (des) proteção social vivida em suas expressões mais cruéis e a violência, inclusive em sua face institucional. Precisamos, ainda, no plano imediato, assumir a defesa intransigente dos direitos desses, ainda meninos e meninas, para assim trilharmos outros caminhos e outra direção social que possa subverter a 
lógica violenta, sancionatória, repressiva e criminalizatória que hoje opera em expansão e sem limites.

\section{Referências}

BARATTA, Alessandro. Criminologia Crítica e Crítica do Direito Penal. 6. ed. Rio de Janeiro: Editora Revan, 2019.

BARATTA, Alessandro. Direitos Humanos: entre a violência estrutural e a violência penal. Rev. Fascículos de ciências penais, Porto Alegre, v. 6, n. 2, p. 44-61, 1993.

BATISTA, Vera Malaguti. Difíceis ganhos fáceis - drogas e juventude no Rio de Janeiro. Rio de Janeiro: Revan, 2003.

BRASIL. Lei no 12.594 de 18 de janeiro de 2012. Dispõe sobre o Sistema Nacional de Atendimento Socioeducativo (SINASE). Brasília (DF), 2012.

BRASIL. Conselho Nacional de Assistência Social. Resolução no 109, de 11 de novembro de 2009. Tipificação Nacional de Serviços Socioassistenciais. Brasília (DF), 2009 .

BRASIL. Resolução n.o 119, de 11 de dezembro de 2006. Dispõe sobre o Sistema Nacional de Atendimento Socioeducativo e dá outras providências. Brasília (DF):

CONANDA, 2006.

CHAUÍ, Marilena Souza. Brasil: mito fundador e sociedade autoritária. São Paulo: Fundação Perseu Abramo, 2000.

CHAUÍ, Marilena Souza. Manifestações ideológicas do autoritarismo brasileiro. São Paulo: Editora Fundação Perseu Abramo, 2013.

ENGELS, Friedrich. Anti-Dühring: a revolução da ciência segundo o senhor Eugen Dühring. Tradução de Nélio Schneider. São Paulo: Boitempo, 2017.

FOUCAULT, Michael. Vigiar e punir: história da violência nas prisões. 42. ed. Petrópolis: Vozes, 2014.

HARVEY, David. Para entender o capital. São Paulo: Boitempo, 2013.

IANNI, Octávio. A sociedade global. Rio de Janeiro: Civilização Brasileira, 2002.

MENDEZ, Emilio Garcia. A criança e seus direitos na América Latina: quando o passado ameaça o futuro. In: CRAIDY, Carmem Maria; SZUCHMAN, Karine (Org.). Socioeducação: fundamentos e práticas. Porto Alegre: Evangraf, 2017, p. 28- 37.

MINAYO, Maria Cecília de S. Violência e saúde. Rio de Janeiro: Editora Fiocruz, 2006. 
SALES, Mione Apolinário. (In)visibilidade perversa: adolescentes infratores como metáfora da violência. São Paulo: Cortez, 2007.

\title{
URIARTE, Carlos E. Vulnerabilidad, privación de libertad de jóvenes y derechos
}

humanos. Montevideo: Fundación de Cultura Universitaria, 2006.

\begin{abstract}
Bruna Carolina BONALUME Trabalhou na concepção e interpretação dos dados, na redação do artigo e na aprovação da versão a ser publicada.

Graduada em Serviço Social pela UNIFAC- Botucatu. Mestre em Saúde Coletiva pela Faculdade de Medicina de Botucatu-UNESP/Botucatu. Doutora em Serviço Social pela Universidade Estadual Paulista (UNESP)- Faculdades de Ciências Humanas e Sociais- campus de Franca. Docente da graduação em Serviço Social da UNIFAC-FIB'S e assistente social do Tribunal de Justiça do Estado de São Paulo. Experiencia em Serviço Social, com atuação nos seguintes temas: Serviço Social; socioeducação; política de atenção à criança e ao adolescente. É integrante do Grupo de Estudos e Pesquisas sobre a dimensão educativa no trabalho social- GEDUCAS.
\end{abstract}

Adriana Giaqueto JACINTO Trabalhou na concepção e interpretação dos dados, na redação do artigo e na aprovação da versão a ser publicada.

Graduada em Letras pela Universidade de Franca; possui graduação, mestrado e doutorado em Serviço Social pela Universidade Estadual Paulista (UNESP)/Franca. Realizou estágio pós-doutoral no Programa de Pós-Graduação em Serviço Social da Faculdade de Serviço Social da Universidade do Estado do Rio de Janeiro (UERJ). Docente do curso de Serviço Social da Faculdade de Ciências Humanas e SociaisUNESP/ Campus de Franca, na graduação e pós graduação. Experiencia em Serviço Social, atuando no ensino-pesquisa-extensão nos seguintes temas: Serviço Social e dimensão educativa; trabalho e formação profissional em Serviço Social; política e assistência social; política de atenção à criança e ao adolescente. É líder do Grupo de Estudos e Pesquisas sobre a dimensão educativa no trabalho social (GEDUCAS).

Argum., Vitória, v. 12, n. 3, p. 181-194, set./dez. 2020. | ISSN 2176-9575 